\title{
Examining the relationship between leader-member exchange (LMX) and objective performance within higher education: An exploratory empirical study
}

\author{
Tim O. Peterson, Ph.D. \\ Professor of Management \\ North Dakota State University \\ Shontarius D. Aikens, Ph.D. \\ Assistant Professor of Management \\ Concordia College
}

\begin{abstract}
While the common suggestion in leader-member exchange (LMX) research is that there is a strong relationship between LMX and performance, a closer look at these studies reveal that the performance measures in the majority of studies are primarily subjective in nature such as performance reviews. Relatively few studies examine the LMX-objective performance (OP) relationship. The findings from those studies are not consistent subjective performance studies. While most LMX studies are conducted in a work environment, this paper adds to the literature by examining this in a higher education. The findings indicated a significantly positive regression coefficient between Professional Respect and midterm grades. Based on the results, the authors introduce the idea of the "peer leader effect" and discussed the development of peer leaders.
\end{abstract}

\section{Introduction}

For the past number of years, leader-member exchange (LMX) research has examined its relationship with a variety of organizational phenomenon. One of the key findings from past researchers is its positive relationship with important leadership and organizational outcomes such as employee satisfaction (Ozer, 2008; Stringer, 2006; Wikaningrum, 2007), employee turnover and absenteeism (Burns \& Otte, 1999), employee commitment (Basu \& Green, 1997), and organizational citizenship behaviors (Hui, Law, \& Chen, 1999; Kent \& Chelladurai, 2001; Wayne, Shore, \& Liden, 1997). The overall effect of a positive supervisor-subordinate relationship results in an overall positive effect to organizational outcomes (Harris, Harris, \& Eplion, 2007).

A key relationship under frequent study is between LMX and job performance. Typical LMX-performance relationship studies (Howell \& Hall-Merenda, 1999; Ouyang, 2009; Schriesheim, Neider, \& Scandura, 1998) indicate that when a positive LMX exists between superior and subordinate, the correlation between LMX and performance is significant and positive. 
A closer look at research studies examining the relationship between LMX and performance reveals a subtle and possible overlooked dynamic. While individual performance can be measured both subjectively (SP) and objectively (OP) (Adler, Thomas, \& Castro, 2005; Borman \& Motowidlo, 1997; Hoffman, Nathan, \& Holden, 1991), the majority of the LMX research has essentially examined the relationship between LMX and subjective performance (SP) which is typically measured through a rating scale of performance that is often called a performance review or appraisal. While some studies incorporate elements of subjective and objective performance in their studies (Howell \& Hall-Merenda, 1999; Kraimer, Wayne, \& Jaworski, 2001; Vecchio, 1998), very few studies examine the relationship solely between LMX and objective performance (OP) which is based on observable results that are relevant to the desired organizational outcomes (Hoffman et al., 1991). In those relatively rare studies that examine the LMX-OP relationship, the findings of a positive and significant relationship are not as consistent with the studies examining the LMX-SP relationship. It has been suggested that future studies examining the relationship between LMX and performance should utilize objective measures of performance rather than subjective measures of performance (Taris, 2006). The purpose of this manuscript is to examine more closely the LMX-OP relationship thus adding to that stream of research.

\section{Theoretical Foundation and Hypotheses}

Leader-Member Exchange. LMX leadership theory examines the individual relationship between the leader and the follower. It can be traced back to its foundations in role theory and social exchange theory (Liden, Wayne, \& Stilwell, 1993). The concept of dyads can be found in the vertical dyad linkage theory in 1978-1983, in which the main thought or concept was that relationships between the leader and each follower are unique (House \& Aditya, 1997). Between 1984-1989, the focus shifted from just recognizing different relationships between a leader and the follower, but also examining the quality of those relationships (House \& Aditya, 1997). In addition, research began to examine the relationship between LMX and other constructs within the organization (Graen \& Uhl-Bien, 1995). The essential premise is that there is a positive relationship between LMX and a variety of organizational objectives.

LMX can be measured using different instruments. The most common instruments are the LMX-7 (Graen \& Uhl-Bien, 1995) which measures LMX on three dimensions (respect, trust, and obligation) and the LMX-MDM (Liden \& Maslyn, 1998) which measures LMX on four dimensions (affect, loyalty, contribution, and professional respect). The LMX-7 is more suited for examining LMX in work related environment according to Graen \& Uhl-Bien (1995).

Measures of Performance. While performance can be measured in aggregate at the organizational level, when considered in the framework of LMX, the shift focuses to performance at the individual level as individual performance is a sub-component of organizational performance. Performance can be classified as either subjective or objective (Adler et al., 2005; Borman \& Motowidlo, 1997; Hoffman et al., 1991). These two forms of measurement are considered distinct and independent categories of job performance (Motowidlo $\&$ Van Scotter, 1994). When measuring objective performance, specific criteria should be used (Hoffman et al., 1991; Wang, Law, \& Chen, 2008). 
Research examining the LMX-OP relationship. While there is a substantial amount of literature which utilizes a subjective measure of performance (i.e. performance ratings), very few research studies utilize an objective measure of performance. Gerstner and Day's (1997) metaanalysis found significant positive correlations between LMX and objective performance, but also indicating that the relationships were stronger when examining LMX and subjective performance. Howell and Hall-Merenda's (1999) study included both subjective and objective components in the performance variable, which resulted in the inability to distinguish a significant relationship between LMX and the objective performance component. Tanner and Castleberry (1990) study combined both subjective and objective measures of performance. However, before the actual study was conducted, a preliminary analysis was conducted which examined LMX in relationship to subjective and objective performance separately. The preliminary findings indicated a marginally significant relationship between LMX and the objective performance measure (Tanner \& Castleberry, 1990).

Given that very few articles examining a pure LMX-OP relationship could be found and that the LMX-OP articles have conflicting results, one can conclude that the research examining the LMX-OP relationship is still in its infancy. Given that most existing LMX research has been conducted in traditional working environments (Ugrin, Odom, and Pearson, 2008), LMX research as a whole should be expanded into other contexts. One example of a context in which LMX has possible applicability and relevance is higher education.

Hypotheses. It is assumed that the study of the LMX-OP relationship is applicable and relevant within higher education. This assumption is based on two factors. One, the fundamental premise of LMX theory are prevalent within higher education. A dyad is one of the foundational components of LMX theory. Interpersonal relationships consist of the quality of the relationship, whether high or low is the foundation of a leader-follower dyad (Deluga, 1994). This type of dyad exists in higher education in a number of forms one of which is teacher-student dyad. The teacher-student dyad has been conceptualized as an interpersonal relationship (Docan-Morgan, 2009). As in a work setting, a higher education environment dyad (teacherstudent) contains a difference in power in which the teacher has more power than the student (Anderson \& Shore, 2008; Biaggio, 2001; Richardson, 1999) especially since the teacher gives the student a grade. There have been previous studies in which the teacher-student relationship has been conceptualized in the context of LMX and used to examine the quality of teacherstudent relationships (Ugrin et al., 2008; Vaughn \& Baker, 2008).

Second, the nature of the educational context allows for a purer examination of the relationship dyad and minimizing the potential effect of power between a supervisor and a subordinate. In a traditional work setting relationship (employer-employee), the managerial power of that relationship can have an influence on performance above and beyond the high or low quality of the relationship. However, in an educational setting, it is completely different in that "subordinates are differentiated not by job title, but by talent, attitude, and personality" (Bess \& Goldman, 2001, p. 440). This helps us to distinguish between a work environment and an educational environment. In a traditional teacher-student relationship, though not a traditional working relationship, there is a still a big power difference albeit less than in a work environment. 
In an educational setting, other dyad types can form. For example, student to student dyads form such as tutoring relationships or peer to peer relationships where one peer assists the other peer in navigating this new learning environment called college. In a peer-to-peer dyad, the power difference is lower than that of a teacher-student dyad. In fact, in a peer-to-peer dyad, the power difference is very small if not nonexistent. Thus, the exchange is mostly based on the relationship quality, whether high or low. This would allow us to really examine the relationship component without any possible influences, visible or not, that could be the result of power differences.

Thus, when considering the LMX-OP relationship within the context of higher education, one must take into consideration that performance measures in higher education differ from those in a traditional work environment. Within higher education, the common performance measure for students is grade point average. The grade point average is a commonly used measure in academic contexts to measure independent performance (Daniels et al., 2009; Hegler, 2004; Robbins, Oh, Le, \& Button, 2009).

For this study, the dyad relationship is a peer-to-peer relationship, where one student is acting as a peer leader to another student to assist them in the socialization process of college. Given the fact that LMX has an effect on individual performance (subjectively) but not so clear cut objectively, and since this is being tested in a new environment, the following hypotheses were developed:

H1: There will be a statistically significant and positive correlation between peer leaders-student LMX and a student's midterm GPA.

H2: There will be a statistically significant and positive correlation between peer leaders-student LMX and a student's term GPA.

Assuming either of these hypotheses are confirmed the next step in this research will be to consider the impact of LMX on midterm GPA and term GPA. This lead to the following two hypotheses:

$\underline{H 3}$ : There will be a statistically significant LMX regression coefficient to midterm GPA.

H4: There will be a statistically significant LMX regression coefficient to term GPA. Again assuming either of these hypotheses are confirmed the next step in this research will be to consider the impact of LMX on midterm GPA and term GPA after controlling for other dependent variables that have been shown in earlier research to have a statistically significant regression coefficient on academic performance measured by GPA. This lead to the following two hypotheses:

H5: After controlling for past research, there will be a statistically significant LMX regression coefficient to midterm GPA.

H6: After controlling for past research, there will be a statistically significant LMX regression coefficient to term GPA.

\section{Research Method}

Population. The population is comprised of freshmen business students at a southwest higher education institution as part of learning community. In this particular context, the freshmen business students have a peer leader assigned who has successfully navigated the first semester in college. Students are classified as first year, first semester freshman business majors 
who were enrolled in an academic credit bearing course as part of a freshman business learning community. Peer leaders are defined as business major students who mentored the first year, first semester freshman business majors that have been assigned to them for the semester in the learning community.

Constructs. LMX: The LMX construct was measured using a modified LMX-MDM scale (Liden \& Maslyn, 1998). The questions were adapted based on the educational environment and the population of peer leaders and freshmen business students. For example, in the original LMX-MDM survey, supervisor was replaced with the words peer leader and superior was replaced with instructor. A completed copy of the modified LMX-MDM survey is located in Table 1. 
Table 1. Modified LMX-MDM Inventory Questions

\begin{tabular}{|c|c|c|}
\hline LMX Dimension & Original LMX-MDM Inventory Item & Modified LMX-MDM Inventory Item \\
\hline Affect & $\begin{array}{l}\text { I like my supervisor very much as a } \\
\text { person. }\end{array}$ & $\begin{array}{l}\text { I like my peer leader very much as a } \\
\text { person. }\end{array}$ \\
\hline Affect & $\begin{array}{l}\text { My supervisor is the kind of person } \\
\text { one would like to have as a friend. }\end{array}$ & $\begin{array}{l}\text { My peer leader is the kind of person } \\
\text { one would like to have as a friend. }\end{array}$ \\
\hline Affect & $\begin{array}{l}\text { My supervisor is a lot of fun to work } \\
\text { with. }\end{array}$ & $\begin{array}{l}\text { My peer leader is a lot of fun to work } \\
\text { with. }\end{array}$ \\
\hline Loyalty & $\begin{array}{l}\text { My supervisor defends my work } \\
\text { actions to a superior, even without } \\
\text { complete knowledge of the issue in } \\
\text { question. }\end{array}$ & $\begin{array}{l}\text { My peer leader defends my work } \\
\text { actions to my instructor, even } \\
\text { without complete knowledge of the } \\
\text { issue in question. }\end{array}$ \\
\hline Loyalty & $\begin{array}{l}\text { My supervisor would come to my } \\
\text { defense if I were "attacked" by } \\
\text { others. }\end{array}$ & $\begin{array}{l}\text { My peer leader would come to my } \\
\text { defense if I were "attacked" by others. }\end{array}$ \\
\hline Loyalty & $\begin{array}{l}\text { My supervisor would defend me to } \\
\text { others in the organization if I made } \\
\text { an honest mistake. }\end{array}$ & $\begin{array}{l}\text { My peer leader would defend me to } \\
\text { others in the organization if I made an } \\
\text { honest mistake. }\end{array}$ \\
\hline Contribution & $\begin{array}{l}\text { I do work for my supervisor that goes } \\
\text { beyond what is specified in my job } \\
\text { description. }\end{array}$ & $\begin{array}{l}\text { I do work for my peer leader that } \\
\text { goes beyond what is expected in the } \\
\text { program. }\end{array}$ \\
\hline Contribution & $\begin{array}{l}\text { I am willing to apply extra efforts, } \\
\text { beyond those normally required, to } \\
\text { meet my supervisor's work goals. }\end{array}$ & $\begin{array}{l}\text { I am willing to apply extra efforts, } \\
\text { beyond those normally required, to } \\
\text { meet my peer leader's work goals. }\end{array}$ \\
\hline Contribution & $\begin{array}{l}\text { I do not mind working my hardest for } \\
\text { my supervisor. }\end{array}$ & $\begin{array}{l}\text { I do not mind working my hardest for } \\
\text { my peer leader. }\end{array}$ \\
\hline Professional & I am impressed with my supervisor's & I am impressed with my peer leader's \\
\hline Respect & knowledge of his/her job. & knowledge of his/her job. \\
\hline $\begin{array}{l}\text { Professional } \\
\text { Respect }\end{array}$ & $\begin{array}{l}\text { I respect my supervisor's knowledge } \\
\text { of and competence on the job. }\end{array}$ & $\begin{array}{l}\text { I respect my peer leader's knowledge } \\
\text { of and competence on the job. }\end{array}$ \\
\hline $\begin{array}{l}\text { Professional } \\
\text { Respect }\end{array}$ & $\begin{array}{l}\text { I admire my supervisor's professional } \\
\text { skills. }\end{array}$ & $\begin{array}{l}\text { I admire my peer leader's } \\
\text { professional skills. }\end{array}$ \\
\hline
\end{tabular}

The quality of the leader-follower relationship can range from being classified as high or low (Liden \& Maslyn, 1998, p. 43). The LMX-MDM scale is more appropriate to use in this environment. This is based on the fact that Graen and Uhl-Bien (1995) suggested that their construct (LMX-7) is more applicable in a working environment. For this study, LMX served as the independent variable that measures the relationship quality between the peer leaders and the freshman students. The LMX data was collected via a survey for a sample of students enrolled in the freshman business learning community.

GPA: Academic performance is measured on a scale ranging from 0.00 to 4.00 . The grades of A, B, C, D, and F earned the points of 4, 3, 2, 1, and 0, respectively. For this particular study, the students were enrolled in their first semester as college students. Thus, the GPA 
variable was captured at Midterm (middle of October) and at the end of the term (December). For this study, Midterm and Term GPA served as a dependent variable. The GPA variable data was collected from institutional records at the conclusion of the semester.

Data Analysis. To test the hypotheses, the following methods were followed. First since the LMX instrument was adapted a confirmatory factor analysis was conducted. Next, at-test was performed to determine if there were any significant differences between the participant sample and the total study population. Third, correlations were run to determine the associations between the LMX and OP variables. Assuming confirmation of a significant and positive relationship between LMX and the objective performance measures, linear regression models were performed to establish a base line. Previous research indicates that higher task performance could be the result of cognitive ability for the individual (Arvey \& Murphy, 1998; Borman \& Motowidlo, 1997; Motowidlo, Borman, \& Schmit, 1997). In addition, other items related to demographics can have an unintended effect on performance outcomes (Stassen, 2003). Thus, to limit any possible effect that cognitive ability or demographics might play, and to limit the study to a pure LMX-OP relationship analysis, college entrance exam scores (ACT) and gender were controlled for in the step-wise regressions. Significance at the .10 significance level was predetermined to be used to either reject or to accept the hypotheses for this exploratory study.

\section{Results}

Since the LMX-MDM instrument was modified, a confirmatory factor analysis was performed to ensure that the four factors as defined by Liden \& Maslyn (1998) were still intact. Table 2 shows the factor loading for the four factors. The Crombach alpha scores and Eigen values are also displayed in this table. The factor loads for all dimensions held and while the Eigenvalue for lolalty was below the 1.0 level the Cronback alpha was strong and so we decide to keep this factor in the construct at this point.

Table 2. Factor Loading, Eigenvalues, Cronbach Alpha for the Modified LMX-MDM

\begin{tabular}{lllll}
\hline Factor Item & Affect & Loyalty & Contribution & Professional Respect \\
\hline 1 & .82 & & & \\
2 & .89 & & & \\
3 & .80 & .83 & & \\
4 & & .82 & & \\
5 & & .69 & .82 & \\
6 & & .85 & \\
7 & & .75 & \\
8 & & & .82 \\
9 & & & .87 \\
10 & & & & \\
11 & & & .09 & 5.60 \\
12 & .88 & .83 & .92 \\
Eigenvalue & 2.03 & .85 & & \\
Cronbach Alpha & .85 & .76 & & \\
\hline
\end{tabular}


A sample of 88 students were randomly selected from the total population of 593 students. To ensure that the sample was representative of the population, a number of demographic values were examined to ensure that the sample represented the population. For example, there were $58(66 \%)$ women students chosen for the study from a total of $322(54 \%)$ women in the population. Likewise, there were $30(34 \%)$ men students chosen for the study from a total of $271(45 \%)$ men in the population. Four other measures of representativeness were tested and the results reported in Table 3 . All showed that there was no significant difference between the sample and population. Therefore, the sample represents the population from which it was drawn.

Table 3. t-Test to Determine the Representativeness of the Sample to the Population

\begin{tabular}{lllllll}
\hline Item & $\mathrm{M}$ & $\mathrm{SD}$ & Target M & $\mathrm{df}$ & $\mathrm{t}$ & $\mathrm{p}$ \\
\hline ACT & 25.75 & 3.69 & 26 & 87 & -.66 & .53 \\
Mid GPA & 2.96 & .67 & 2.89 & 87 & .96 & .34 \\
Term GPA & 3.34 & .51 & 3.29 & 87 & .85 & .40 \\
\hline
\end{tabular}

While there were only 88 freshmen involved in the study, each freshman had two peer leaders. Each of the 88 freshmen completed the LMX survey on each of their peer leaders making for 176 dyads.

Table 4 details the means, standard deviations, and correlations for the study variables. The correlations of interest for Hypothesis 1 are located on row five. As can be seen the Professional Respect dimension of LMX-DMD is positively significant with Mid-term GPA. This partially confirms Hypothesis 1 . At the same time Hypothesis 2 was not confirmed which is shown in row six. More about why this might happen will be shared in the discussion session of the manuscript.

Table 4. Mean, Standard Deviation and Intercorrelations for Study Variables

\begin{tabular}{|c|c|c|c|c|c|c|c|c|}
\hline Measures & M & SD & 1 & 2 & 3 & 4 & 5 & 6 \\
\hline 1. Affect & 14.16 & 1.51 & -- & & & & & \\
\hline 2. Loyalty & 13.15 & 2.01 & $.25 * *$ & -- & & & & \\
\hline 3. Contribution & 12.89 & 2.26 & $.35 * *$ & $.59 * *$ & -- & & & \\
\hline 4. Professional Respect & 13.91 & 1.99 & $.55 * *$ & $.46^{* *}$ & $.46^{* *}$ & -- & & \\
\hline 5. Mid-term GPA & 2.96 & .67 & .05 & .01 & .04 & $.14^{*}$ & -- & \\
\hline 6. Term GPA & 3.34 & .51 & .00 & -.06 & .06 & .06 & $.77 * *$ & -- \\
\hline
\end{tabular}


At this point because Hypothesis 1 was confirmed by one of the dimensions of the LMXMDM, we continued on to examine Hypothesis 3 which is: There will be a statistically significant LMX regression coefficient to midterm GPA. Hypothesis 4 will no longer be considered since Hypothesis 2 was not confirmed; however, possible reasons for this result will be discussed later. Table 5 shows the results of the regression between the dependent variable Mid-term GPA and the independent variable Professional Respect. Since this is an exploratory study in a new environment and a very different subject type, we have pre-determined that at this stage a .10 level of significance is appropriate to move forward with our analysis. As can be seen in Table 5 the Professional Respect meets this threshold at .06. In this study the intercept carries meaning. The freshmen involved in this study would have a $2.31 \mathrm{GPA}$ at mid-term assuming no other intervening factors. The independent variable Professional Respect adds an additional .05 for each increment of this variable. So for example, assuming a freshman had a peer leader that they rated as a 15 on Professional Respect, the highest possible score, that student's Mid-term GPA could rise by as much as three-fours of a letter grade to 3.06 [2.31+ $(.05 * 15)=3.06]$. More about why Professional respect might play a significant role in a freshman's GPA will be presented in the discussion session.

Table 5. Regression Analysis Summary for Mid-term GPA and Professional Respect

\begin{tabular}{lllll}
\hline Model & $\mathrm{B}$ & SE B & $\mathrm{t}$ & Sig \\
\hline Intercept & 2.31 & .35 & 6.52 & .000 \\
Professional Respect & .05 & .03 & 1.85 & .066 \\
\hline
\end{tabular}

$\mathrm{R}^{2}=.02(\mathrm{~N}=176, \mathrm{p}<.10)$

Given this finding, we moved on to examine Hypothesis 5 which is: After controlling for past research, there will be a statistically significant LMX regression coefficient to midterm GPA. As stated earlier in the manuscript, previous research has shown that cognitive ability (Arvey \& Murphy, 1998; Borman \& Motowidlo, 1997; Motowidlo et al., 1997) and demographics (Stassen, 2003) can affect performance. In this study, we used ACT scores to control for cognitive ability and gender since research has shown in the past that women often have higher GPA's than men.

Table 6 shows the stepwise regression analysis by controlling for cognitive ability and gender before entering the dimension of Professional Respect from the LMX-MDM instrument. The first thing to notice is that gender was excluded from the model as non-significant $(t=.18, p$ $=.86$ ). However, both ACT and Professional Respect remained in Model 2 and were significant contributors to Mid-term GPA. For example, a freshman who had an average ACT score of 26 according to the population, should have a Mid-term GPA of $2.33[.51=(.07 * 26)]=2.33]$ before consideration of Professional Respect. When considering Professional Respect into the equation assuming a score of 15 for professional Respect, the freshman Mid-term GPA could go up to as high as $3.08[.51+(.07 * 26)+(.05 * 15)=3.08]$. The next section will discuss the implications of these findings, the limitations to the study, and future research directions. 
Table 6. Regression Analysis Summary Controlling for Cognitive Ability and Gender with Mid-term GPA and Professional Respect

\begin{tabular}{lllll}
\hline Model & $\mathrm{B}$ & SE B & $\mathrm{t}$ & Sig \\
\hline Step 1 - ACT Score & & & & \\
Intercept & 1.31 & .33 & 3.90 & .000 \\
ACT Score & .06 & .01 & 4.99 & .000 \\
Step 2 - Professional Respect & & & & \\
Intercept & .51 & .48 & 1.06 & .29 \\
ACT Score & .07 & .01 & 5.18 & .000 \\
Professional Respect & .05 & .02 & 2.29 & .02 \\
\hline
\end{tabular}
$\mathrm{R}^{2}=.15(\mathrm{~N}=176, \mathrm{p}<.10)$

\section{Discussion}

Implications and Impacts of the Study. The results of this study provide an interesting glimpse into how LMX plays a role within a higher education setting. Using the LMX-MDM allowed us to closely examine which sub-dimensions of LMX affect objective performance. The findings of a significant positive correlation between Professional Respect and midterm grades, while there was no significant positive correlation between Professional Respect and term grades, can be explained rather easily. Figure 1 illustrates the $\mathrm{W}$ curve proposed by Gullahorn and Gullahorn (1963) as a way to illustrate and describe culture shock. This model has been adapted and used to describe the transition period and significant events experienced by students returning from overseas (Gaw, 2000; Oberg, 1960) as well as first year college students (Hoffenberger, Mosier, \& Stokes, 1999).

\section{A. Honeymoon}

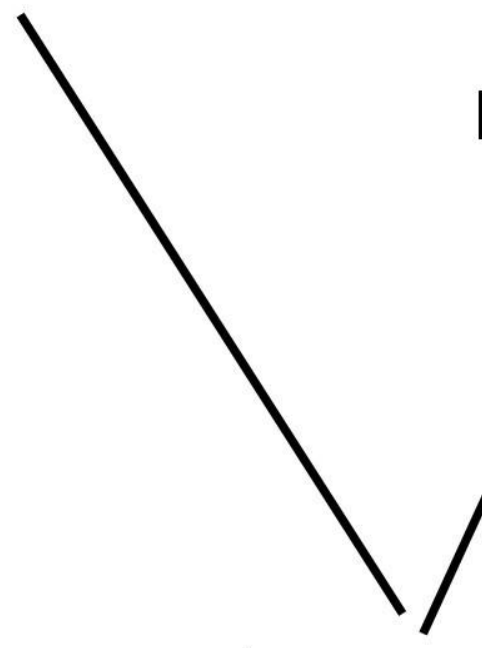

B. Culture Shock
C. Initial Adjustment

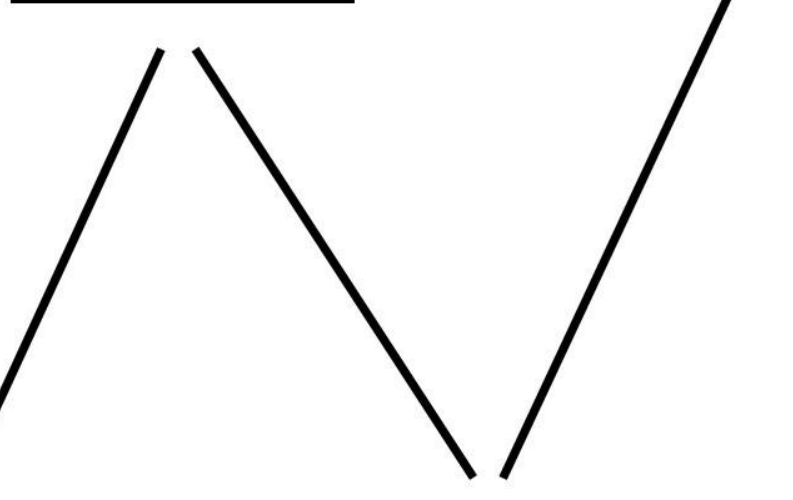

D. Mental Isolation

Figure 1. W Curve of Culture Shock. 
Figure 2 illustrates an expanded $\mathrm{W}$ curve for first year students to include cognitive and affective responses to the culture shock of college. As first year students prepare to leave for college they are excited and anticipate the new opportunity to live on their own. The staff and faculty at the university are welcoming. The students are looking forward to the new adventure. However, shortly after arriving, the expectations do not match with reality. The student might discover that they are not as well prepared as they anticipated or that their new roommates do not conform to their expectation. They find it difficult to get around because they are in new surroundings and the excitement wears off. One of the major causes of college culture shock is the academic rigor of classes at the college level. They receive their first round of examinations or papers and in many cases their grades are not consistent with their past academic experiences. In most cases, these first year students have received good grades through high school or they would have not been admitted to college. This new reality is a shock to their cognitive/affective system. So, they start to feel lost, self-doubt creeps in, and they may start to withdraw.

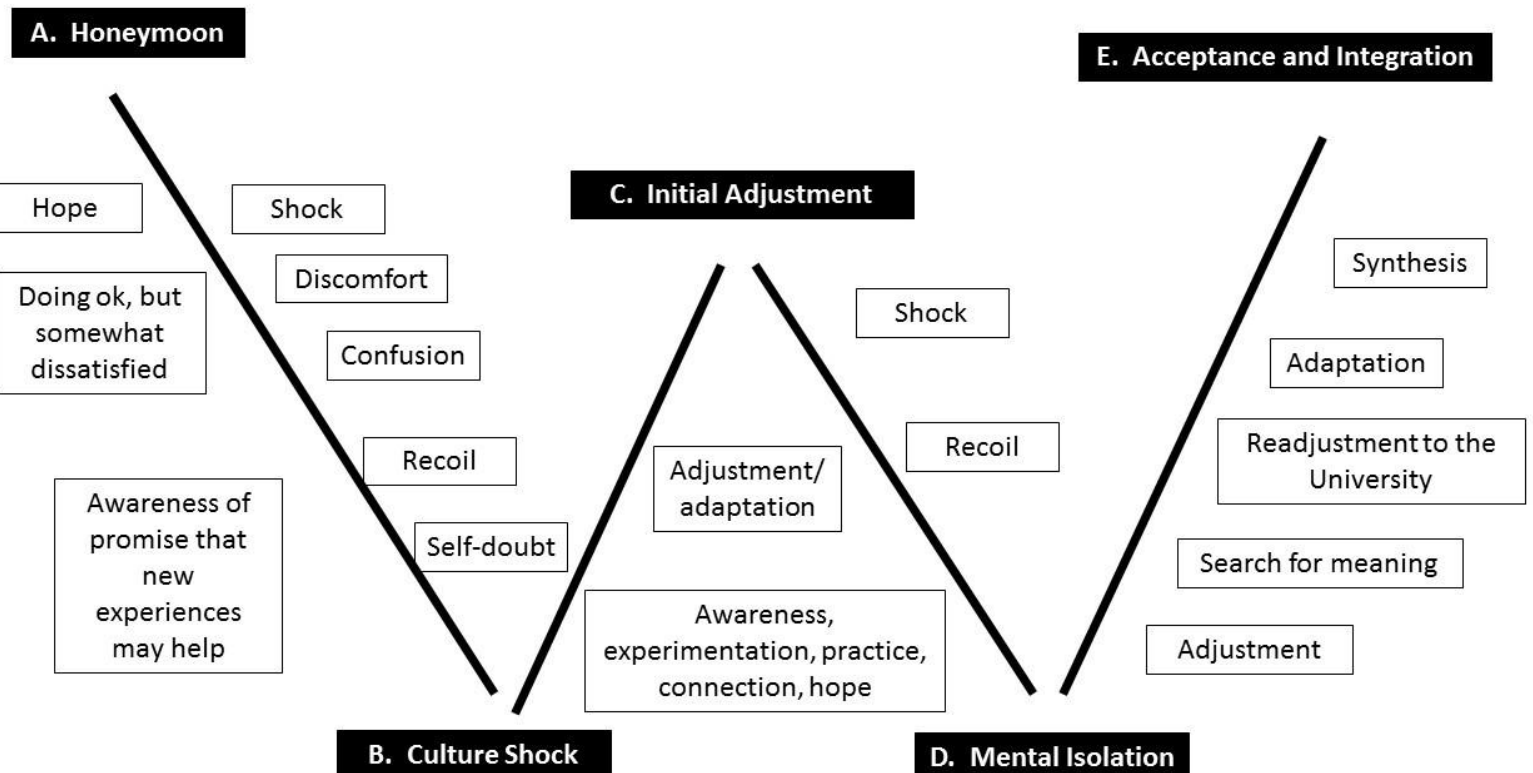

Figure 2. Cognitive and Affect Responses to W Curve of Culture shock

The W curve helps frame our discussion as it relates to LMX. When first year students come to college, they come to college on a high. Ender and Newton (2000) describe a variety of challenges that first year students experience (personal adjustments, physical challenges, interpersonal challenges, career and lifestyle challenges, and intellectual and academic challenges). The culmination of these challenges creates an experience of shock that occurs around the midterm time frame (the low point of the $\mathrm{W}$ curve). But, at this point, the curve goes back up assuming that the students have started to adjust to college and the many challenges. One way to prevent this curve from being so deep could be by having someone you respected professionally. For example, someone who had navigated the system beforehand. This could 
benefit the first year student in enhancing their introduction to college. Ender and Newton (2000, p. 44) have suggested that "being able to observe and interact with others who effectively model the characteristics, values, and processes that best represent the outcomes to which the environment is committed" is one way to provide conditions that promote student development. This is the role of a peer leader. Our findings would indicate that when a first year student has a peer leader who they respect professionally the curve is not as deep and the first year student adjusts quicker to their academic environment and perform better earlier. We have named this the peer leader effect and it is illustrated in Figure 3.

A. Honeymoon

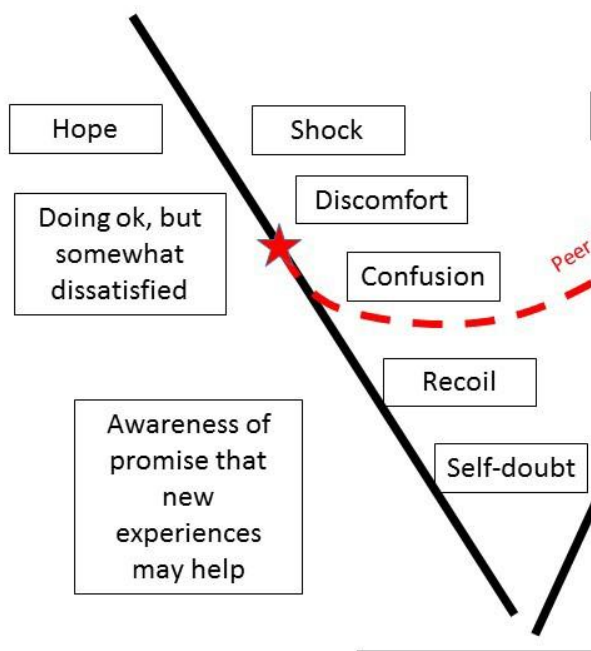

B. Culture Shock
E. Acceptance and Integration

C. Initial Adjustment

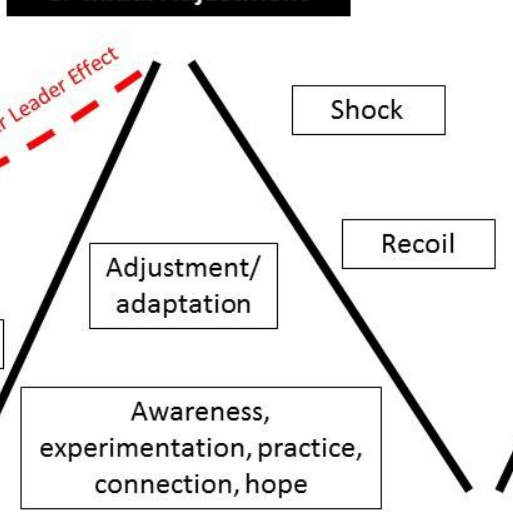

D. Mental Isolation

Figure 3. Peer Leader Effect Applied to the W Curve

In this figure, the peer leader effect occurs before midterms and softs the college culture shock. For example, if a first year student rates their peer leader on the professional respect scale as a 15 , which is the highest score a peer leader could receive, the student could potentially have a mid-term grade point of 3.06 (Estimated Mid-term Grade Point $=2.31+(.05 * 15=3.06$ ). On the other hand, if the first year student rated their peer leader on professional respect as a 5 , which is the lowest score a peer leader could receive, the student could potentially have a midterm grade point of 2.56 (Estimated Mid-term Grade Point $=2.31+(.05 * 5=2.54)$. These results are confirmed by the significant and positive correlation between the professional respect variable and Mid-Term GPA variable in Table 4 and the regression model in Table 5. On a more practical note, at the university where this data was collected, students had to maintain a 2.5 GPA to remain in good standing with the College of Business. Without peer leaders, both examples above would have a projected mid-term GPA of 2.31 and would be put on probation but the peer leader effect raises both up to an acceptable mid-term GPA. 
However, the peer leader effect seems to wear off around mid-term and so we see no significant positive correlation or significant coefficient for term GPA.

Framing this in LMX terms, several implications can be made. First, the basis for Professional Respect having a significant effect on mid-term GPA is that first year students should perceive peer leaders as having expert power. In the leadership and management literature, French and Raven (1960) define expert power as power based on one's expertise or specialized knowledge not possessed by others within the organization. Some examples of behavior associated with expert power consist of the peer leaders understanding the expectations of the professors, knowing how to access resources on campus, or knowing how to register for classes after the first semester. These behaviors and characteristics are in direct alignment with the Professional Respect construct, thus indicating congruence between these two dimensions/constructs. The general expectations of Professional Respect apply in this setting as well. First year students look up to peer leaders who have successfully navigated the first year of college.

Second, the Professional Respect dimension encompasses leadership behaviors found by previous researchers that are needed to be successful. Effective leadership occurs when a) the relationship between the leader and the follower is based on credibility (Kouzes \& Posner, 2003) and b) a leader exhibits five leadership practices or behaviors: model the way, inspire a shared vision, challenge the process, enable others to act, and encourage the heart (Kouzes \& Posner, 2012). As applied in this situation, the Professional Respect dimension measures the credibility piece of the leader-follower dyad. Once that is established, the most applicable leadership practice is modeling the way. If a peer leader successfully provides an example of what to do and what not to do for first year students over the first part of a semester, then eventually the effectiveness goes away by the end of the semester. Or, another way of presenting it is that the peer leaders serve as a form of scaffolding for the first year student.

While the results are clear in why Professional Respect is significant, it is important to discuss implications or reasons why the other LMX dimensions were not deemed to be significant. The overall implication is that the remaining dimensions (affect, contribution, and loyalty) are not applicable within this setting and in the peer leader-student dyads. The Affect dimension is defined as "the mutual affection members of the dyad have for each other based primarily on interpersonal attraction, rather than work or professional values" (Liden \& Maslyn, 1998, p. 50). Peer leaders are trained and are constantly reminded that they are not supposed to be friends with their first year students. In fact, they are to treat this position just as if it was a job or work. This could explain why Affect was not significantly correlated with the performance measures. The Contribution dimension is defined as "perception of the current level of work-oriented activity each member puts forth toward the mutual goals explicitly or implicitly of the dyad" (Liden \& Maslyn, 1998, p. 50). In this context, first year students are not working for the peer leaders, but in actuality are working for themselves. This could explain why Contribution was not significantly correlated with the performance measures. The Loyalty dimension is defined as "the expression of public support for the goals and the personal character of the other member of the LMX dyad" (Liden \& Maslyn, 1998, p. 50). It should be noted that the findings of this study suggest a somewhat negative correlation between Loyalty and performance (i.e. term GPA) which is the only negative correlations found in the study. Peer 
leaders who try to extract loyalty from their first year students actually harm the relationship by making the first year students too dependent on them. This is not the purpose of a peer leader. A peer leader is there to cushion the college cultural shock and to assist the first year student in making that adjustment.

Third, the finding provides implications regarding the effectiveness timeline of peer leaders. Another way of phrasing this is the law of diminishing returns. Table 4 indicates that all correlations, except for one (Contribution), decrease between point A (midterm) and point B (end of term). This supports the fact that peer leaders and what they can offer in terms of a LMX framework decreases after midterms. This is supported with the incline on the W'curve from midterm to end of the term. If Professional Respect is so critical to the relationship between peer leaders and first year students and the cushioning of the college cultural shock what type of development needs to occur for peer leaders before the new students arrive?

Development of Peer Leaders' Expertise (Professional Respect) One of the critical events that must occur is that the instructor must make it clear to the first year students that the peer leaders have successfully navigated the college system and are knowledgeable on how to be successful. This cannot be over emphasized. First year students are looking for ways to successfully navigate the system. These new students often look to the instructor for guidance. By emphasizing the expertise of the peer leaders, the instructor provides the peer leaders with credibility.

Ender and Newton (2000) is an excellent resource for developing peer leaders' expertise. It has excellent chapters on academic success (Chapter 8), campus resources (Chapter 9) and general good academic practices (Chapter10). This material is important to provide content but not sufficient in developing the peer leader. Peer leaders must develop a more comprehensive understanding of how people learn and develop over time. Ender and Newton point out that all human growth and development occurs as a result of pressure from the environment. So entering college puts pressure on the first year students to learn and develop. It is critical to get the peer leaders to understand that their responsibilities are to mentor, coach, and guide the first year student. Conversely, it is not their responsibility to shelter, to do the work for the first year student, or to prevent the first year students from facing the challenges of college life.

It is important that peer leaders become familiar with the types of challenges that first year students experience. Do not assume that your peer leaders have experienced all or even some of these challenges. Quite often peer leaders found the navigation of the first year easy. So they need to be introduced to the challenges that the average first year student might experience. Chickering and Reisser (1993) identified seven development areas that are very common for the first year student. They are: 1) developing a sense of personal competence, 2) managing emotions effectively, 3) learning to think and act on one's own, 4) formulating a personal self-concept, 5) building interpersonal relationships, 6) envisioning a sense of purpose, and 7) defining core values and beliefs from which to make personal choices.

These seven developmental areas run headlong into the challenges facing first year students. Such as living with a roommate who is ethnically different, how to speak up in class in order to demonstrate engagement, learning to deal with stressful situations on one's own, being 
able to assert one's self around issue of alcohol and drug consumption, and choosing an academic major and future career path. Peer leaders must understand again their role is to mentor, coach, guide in these issues not direct, tell, or mandate and answer.

Limitations and Future Directions. Several limitations to this study should be mentioned. First, we were only permitted to take a sample of the population. This was due to our direct involvement in the program. Second, the sample only comes from one southwestern institution. In the future, we would like to collect a larger sample. In addition, we would like to collect data from other instructions that have peer leadership programs. Finally, it is speculated that the significant positive $\mathrm{p}$-value of .066 would go down with in the normal rigorous level of .05 assuming a larger sample. Again this is a critical reason to repeat the student with a larger sample.

\section{Conclusions}

The above study was an attempt to examine the LMX and performance dynamic from an objective performance standpoint. As mentioned earlier, the majority of previous research examines the LMX-performance relationship mostly from a subjective performance perspective. By examining it in a different context and from a LMX-objective performance perspective, our hope is to open up a new stream of research and to expand the findings outside of the traditional work environment.

As educational institutions consider having peer to peer structures, it is important for them to have an exceptional instructional method for developing the peer leaders so they are seen as having expert power which established credibility within the peer leaders and leads to professional respect. While peer leaders can add to objective performance measures (GPA), what is most significant is the expert knowledge perceived by the first year students that leads the peer leader effect that softens the college cultural shock. 


\section{References}

Adler, A. B., Thomas, J. L., \& Castro, C. A. (2005). Measuring up: Comparing self-reports with unit records for assessing soldier performance. Military Psychology, 17(1), 3-24. doi: 10.1207/s15327876mp1701_2

Anderson, D. D., \& Shore, W. J. (2008). Ethical issues and concerns associated with mentoring undergraduate students. Ethics \& Behavior, 18(1), 1-25. doi: $10.1080 / 10508420701519577$

Arvey, R. D., \& Murphy, K. R. (1998). Performance evaluation in work settings. Annual Review of Psychology, 49, 141-168. doi: 10.1146/annurev.psych.49.1.141

Basu, R., \& Green, S. G. (1997). Leader-member exchange and transformational leadership: An empirical examination of innovative behaviors in leader-member dyads. Journal of Applied Social Psychology, 27(6), 477-499. doi: 10.1111/j.1559-1816.1997.tb00643.x

Bess, J. L., \& Goldman, P. (2001). Leadership ambiguity in universities and K-12 schools and the limits of contemporary leadership theory. The Leadership Quarterly, 12(4), 419-450. doi: 10.1016/s1048-9843(01)00090-x

Biaggio, M. (2001). Navigating roles in mentoring relationships with graduate students. Retrieved from ERIC database. (ED457516)

Borman, W. C., \& Motowidlo, S. J. (1997). Task performance and contextual performance: The meaning for personnel selection research. Human Performance, 10(2), 99-109. doi: 10.1207/s15327043hup1002_3

Burns, J. Z., \& Otte, F. L. (1999). Implications of leader-member exchange theory and research for human resource development research. Human Resource Development Quarterly, 10(3), 225-248. doi: 10.1002/hrdq.3920100304

Chickering, A.W. \& Reisser, L. (1993). Education and identity. San Francisco, CA: Jossey-Bass.

Daniels, L. M., Stupnisky, R. H., Pekrun, R., Haynes, T. L., Perry, R. P., \& Newall, N. E. (2009). A longitudinal analysis of achievement goals: From affective antecedents to emotional effects and achievement outcomes. Journal of Educational Psychology, 101(4), 948963. doi: 10.1037/a0016096

Deluga, R. J. (1994). Supervisor trust building, leader-member exchange and organizational citizenship behaviour. Journal of Occupational \& Organizational Psychology, 67(4), 315-326. doi: 10.1111/j.2044-8325.1994.tb00570.x

Docan-Morgan, T. (2009). A typology of relational turning point events in college teacherstudent relationships. Journal of the Scholarship of Teaching and Learning, 9(2), 82-97.

Ender, S. C., \& Newton, F. B. (2000). Students helping students: A guide for peer educators on College Campuses. San Francisco, CA: Jossey-Bass. 
French, J. R. P., \& Raven, B. (1960). The bases of social power. In D. Cartwright \& A. Zander (Eds.), Group dynamics: Research and theory (2nd ed., pp. 607-623). Evanston, Illinois: Row, Peterson and Company.

Gaw, K. F. (2000). Reverse culture shock in students returning from overseas. International Journal of Intercultural Relations, 24(1), 83-104.

Gerstner, C. R., \& Day, D. V. (1997). Meta-analytic review of leader-member exchange theory: Correlates and construct issues. Journal of Applied Psychology, 82(6), 827-844. doi: 10.1037/0021-9010.82.6.827

Graen, G. B., \& Uhl-Bien, M. (1995). Relationship-based approach to leadership: Development of leader-member exchange (LMX) theory of leadership over 25 years: Applying a multilevel multi-domain perspective. The Leadership Quarterly, 6(2), 219-247. doi: 10.1016/1048-9843(95)90036-5

Gullahorn, J. T., \& Gullahorn, J. E. (1963). An Extension of the U-Curve Hypothesis. Journal of Social Issues, 19(3), 33-47. doi: 10.1111/j.1540-4560.1963.tb00447.x

Harris, K. J., Harris, R. B., \& Eplion, D. M. (2007). Personality, leader-member exchanges, and work outcomes. Journal of Behavioral \& Applied Management, 8(2), 92-107.

Hegler, K. L. (2004). Assessing learning communities. Assessment Update, 16(6), 1-8.

Hoffenberger, K., Mosier, R., \& Stokes, B. (1999). Transition experience. In J. H. Schuh (Ed.), Educational programming and student learning in college and university residence halls: ACUHO-I.

Hoffman, C. C., Nathan, B. R., \& Holden, L. M. (1991). A comparison of validation criteria: Objective versus subjective performance measures and self-versus supervisor ratings. Personnel Psychology, 44(3), 601-619.

House, R. J., \& Aditya, R. N. (1997). The social scientific study of leadership: Quo vadis? Journal of Management, 23(3), 409-473. doi: 10.1177/014920639702300306

Howell, J. M., \& Hall-Merenda, K. E. (1999). The ties that bind: The impact of leader-member exchange, transformational and transactional leadership, and distance on predicting follower performance. Journal of Applied Psychology, 84(5), 680-694. doi: $\{10.1037 / 0021-9010.84 .5 .680$

Hui, C., Law, K. S., \& Chen, Z. X. (1999). A structural equation model of the effects of negative affectivity, leader-member exchange, and perceived job mobility on in-role and extra-role performance: A Chinese case. Organizational Behavior and Human Decision Processes, 77(1), 3-21. doi: 10.1006/obhd.1998.2812

Kent, A., \& Chelladurai, P. (2001). Perceived transformational leadership, organizational commitment, and citizenship behavior: A case study in intercollegiate athletics. Journal of Sport Management, 15(2), 135. doi: 10.1123/jsm.15.2.135 
Kouzes, J. M., \& Posner, B. Z. (2003). Credibility: How leaders gain and lose it, why people demand it. San Francisco, CA: Jossey-Bass.

Kouzes, J. M., \& Posner, B. Z. (2012). The leadership challenge: How to make extraordinary things happen in organizations (5th ed.). San Francisco, CA: Jossey-Bass.

Kraimer, M. L., Wayne, S. J., \& Jaworski, R. A. (2001). Sources of support and expatriate performance: The mediating role of expatriate adjustment. Personnel Psychology, 54(1), 71-99. doi: 10.1111/j.1744-6570.2001.tb00086.x

Liden, R. C., \& Maslyn, J. M. (1998). Multidimensionality of leader-member exchange: An empirical assessment through scale development. Journal of Management, 24(1), 43-72. doi: $10.1177 / 014920639802400105$

Liden, R. C., Wayne, S. J., \& Stilwell, D. (1993). A longitudinal study on the early development of leader-member exchanges. Journal of Applied Psychology, 78(4), 662-674. doi: 10.1037/0021-9010.78.4.662

Motowidlo, S. J., Borman, W. C., \& Schmit, M. J. (1997). A theory of individual differences in task and contextual performance. Human Performance, 10(2), 71-83. doi: 10.1207/s15327043hup1002_1

Motowidlo, S. J., \& Van Scotter, J. R. (1994). Evidence that task performance should be distinguished from contextual performance. Journal of Applied Psychology, 79(4), 475480. doi: 10.1037/0021-9010.79.4.475

Oberg, K. (1960). Culture shock adjustment to new cultural environments. Practical Anthropology, 7, 177-182.

Ouyang, Y. (2009). An investigation of the effects of leader member exchange on job performance in Taiwan. Business Renaissance Quarterly, 4(3), 109-127.

Ozer, M. (2008). Personal and task-related moderators of leader-member exchange among software developers. Journal of Applied Psychology, 93(5), 1174-1182. doi: 10.1037/0021-9010.93.5.1174

Richardson, S. M. (1999). Civility, leadership, and the classroom. New Directions for Teaching \& Learning, 77, 77-86. doi: 10.1002/t1.7708

Robbins, S. B., Oh, I.-S., Le, H., \& Button, C. (2009). Intervention effects on college performance and retention as mediated by motivational, emotional, and social control factors: Integrated meta-analytic path analyses. Journal of Applied Psychology, 94(5), 1163-1184. doi: 10.1037/a0015738 
Schriesheim, C. A., Neider, L. L., \& Scandura, T. A. (1998). Delegation and leader-member exchange: Main effects, moderators, and measurement issues. Academy of Management Journal, 41(3), 298-318. doi: 10.2307/256909

Stassen, M. L. A. (2003). Student outcomes: The impact of varying living-learning community models. Research in Higher Education, 44(5), 581-613. doi: 0.1023/a:1025495309569

Stringer, L. (2006). The link between the quality of the supervisor-employee relationship and the level of the employee's job satisfaction. Public Organization Review, 6(2), 125-142. doi: 10.1007/s11115-006-0005-0

Tanner, J. F., Jr., \& Castleberry, S. B. (1990). Vertical exchange quality and performance: Studying the role of the sales manager. Journal of Personal Selling \& Sales Management, 10(2), 17-27.

Taris, T. W. (2006). Is there a relationship between burnout and objective performance? A critical review of 16 studies. Work \& Stress, 20(4), 316-334. doi:10.1080/02678370601065893

Ugrin, J. C., Odom, M. D., \& Pearson, J. M. (2008). Exploring the importance of mentoring for new scholars: A social exchange perspective. Journal of Information Systems Education, 19(3), 343-350.

University of Wisconsin Superior. (2016). The W-Curve Hypothesis Model. Retrieved from https://www.uwsuper.edu/fye/parents/upload/W-Curve.pdf

Vaughn, L. M., \& Baker, R. C. (2008). Do different pairings of teaching styles and learning styles make a difference? Preceptor and resident perceptions. Teaching \& Learning in Medicine, 20(3), 239-247. doi: 10.1080/10401330802199559

Vecchio, R. P. (1998). Leader-member exchange, objective performance, employment duration, and supervisor ratings: Testing for moderation and mediation. Journal of Business \& Psychology, 12(3), 327-341. doi: 10.1023/a:1025027514081

Wang, H., Law, K. S., \& Chen, Z. X. (2008). Leader-member exchange, employee performance, and work outcomes: An empirical study in the Chinese context. International Journal of Human Resource Management, 19(10), 1809-1824. doi: 10.1080/09585190802323926

Wayne, S. J., Shore, L. M., \& Liden, R. C. (1997). Perceived organizational support and leadermember exchange: A social exchange perspective. Academy of Management Journal, 40(1), 82-111. doi:10.2307/257021

Wikaningrum, T. (2007). Coworker exchange, leader-member exchange, and work attitudes. Gadjah Mada International Journal of Business, 9(2), 187-215. 


\section{Author Biographies}

Tim O. Peterson is Professor of Management in the College of Business at North Dakota State University. He teaches classes in the vital competencies needed to be a good organizational citizen. Prior to starting his academic career, Tim served for 25 years in the U.S. Air Force. Email is tim.o.peterson@ndsu.edu.

Shontarius D. Aikens is Assistant Professor of Management in the Offutt School of Business at Concordia College in Moorhead, Minnesota. He teaches undergraduate courses in leadership, organizational behavior, and entrepreneurship. Prior to Concordia College, he was the AACSB Accreditation Manager at North Dakota State University. Email is saikens@cord.edu. 